International Journal of Advanced Biological and Biomedical Research

Available online at http:www.ijabbr.com

Volume 7, Issue 2 (2019) pp. 142-150

Original Article

\title{
Evaluation of the Expression of the CK-18 Tumor Marker in Blood Samples of Breast Cancer Patients using Real- Time PCR
}

\section{Armin Gharibi*, Roudabeh Behzadi Andouhjerdi}

Department of genetic, Islamic Azad University of Central Tehran Branch, Tehran, Iran

*Corresponding Author E-mail: arming8989@yahoo.com

Received: 15 December 2018, Revised: 2 February 2019, Accepted: 18 February 2019

\begin{abstract}
Background: Cytokeratins (CK) are the largest subgroup of interstitial proteins, and their expression changes during the development of cancer. Cytokeratin (CK-18) is one of the major proteins of the epithelial cell skeleton. The expression potential of the CK-18 gene was studied in this research as a molecular biomarker for the diagnosis of breast cancer in the circulatory system using the Real-Time PCR technique. Methods: Blood samples of breast cancer patients and healthy individuals (as the control group) were collected from the Cancer Institute of Imam Khomeini Hospital, Tehran, Iran and their RNA was extracted. In the next step, the cDNA molecule was synthesized using a reverse transcriptase enzyme (RT), and gene-specific primers were designed and synthesized. Then, the expression of CK-18 tumor marker was evaluated by the real-time PCR technique; finally, the data obtained from the cancer samples and the control group was analyzed by the SPSS software.
\end{abstract}

Results: CK-18 expression was observed and measured in the patients' serum .In addition, according to the disease grade, the CK-18 expression was different in the patients, serum. Conclusions: The findings of this research can be used in future studies exploring the mechanism of action of this gene as a suitable target for the treatment of breast cancer.

Key words: Circulating tumor cells (CTC), Breast cancer, CK-18, tumor marker, Real-time PCR.

\section{Introduction}

Brest cancer is one of the most common cancers in women worldwide, accounting for approximately 570,000 deaths in 2015 . Over 1.5 million women (25\% of all women with cancer) are diagnosed with Breast cancer every year throughout the word (Stevart et al., 2014, 2). In America, it is estimated that 30\% of all new cancer cases $(252,710)$ among women are breast cancer in 2017 (Siegel et al., 2017). Breast cancer is a metastatic cancer and can commonly transfer to distant organs such as the bone, liver, lung and brain, which mainly accounts for its incurability. Early diagnosis of the disease can lead to a good prognosis and a high survival rate. In North American, the 5year relative survival rate of breast cancer patients is above $80 \%$ due to the timely detection of this disease (DeSantis et al., 2016). In Iran, incidence, mortality and 5 -year 
prevalence of breast cancer in 2012 was estimated $24.5 \%$ and $37.7 \%$ respectively (Siegel et al., 2014). Since this type of cancer develops in women at an age when the maximum individual, familial, and social efficiency is required, attention to this disease is of particular importance (Katapodi et al., 2009). One of the most common methods used in the diagnosis of cancer involves laboratory tests using Circulating Tumor Cells (Salehi Nodeh et al., 2008). Tumor markers are the factors present in the blood, urine, or body tissues, and their increase or decrease can be used for various purposes, such as in the screening, diagnosis, prognosis, or treatment of diseases (8). CTC are rare cells released into the blood stream by primary or metastatic tumors (Baccelli et al., 2013, zhang et al., 2013). CTC have been identified in many solid tumors including breast (Cristofanilli et al., 2004), prostate (Makarovskiy et al., 1997), lung (Allard et al., 2004), bladder (Naoe et al., 2007), gastric (Wolfrum et al., 2005), and colon cancer (Choy et al., 1993), while they are rarely found in healthy people or in people with nonmalignant tumor (Allard et al., 2004). Tumor markers can be considered as the molecule that determines the likelihood of cancer or provides information about the cancers probability and behavior, such as metastasis and its spread, and the likelihood of cancer relapse and/or recurrence (Schrohl et al., 2003). Cytokeratins are the largest subgroup of interstitial string proteins that exist as more than 20 different varieties (Chu et al., 2002). During the development of cancer, the main expression profile of the $\mathrm{CK}$ is altered to the extent that different pattern of expression of cytokeratins can sometimes detect different types of breast cancers (Shao et al., 2012). Cytokeratin-18 (CK-18) is one of the important proteins of the epithelial cells skeletal system that is involved in the process of metastasis in breast cancer patients (Alix-Panabieres et al., 2009). Out of all the CK proteins, CK-18, and CK-19 are the most frequent cytokeratins found in cancerous cells (Dive et al., 2010). Real-time PCR is a strong and cost-effective technique, previously used to identify solid tumors and infections, and routinely for the diagnosis of cancers and infectious diseases. In this study, we used this technique to detect the circulating tumor cells (CTCs) from the peripheral blood of breast cancer patients, which has several advantages. In addition, with the use of this technique we could avoid the need for bone marrow aspiration or biopsy for the analysis of the specimens (Bernard et al., 2002).

\section{Materials and Methods}

The peripheral blood samples were collected from 30 patients with breast cancer; the cancer was confirmed by biopsy and complementary tests by pathologists using the immunohistochemistry (IHC) assay, and blood samples of 30 subjects who received negative results in three consecutive tests in ultrasound and mammography were selected as the control group. These blood samples were collected from the Cancer Institute of the Imam Khomeini Hospital. The RNA was extracted from each sample according to the RNX-PLUS kit Instructions (CINACLONE Company). The quality of the extracted mRNA was investigated by a qualitative method using the nanodrop device, model 2000, Termo Scientific USA Company using optical absorption at wavelengths of 260 and $280 \mathrm{~nm}$.

The complementary ribonucleotid acid (cDNA) was synthesized using the Reverse Transcriptase (RT) enzyme by using Malaysian Vivantis cDNA synthesis kits. In the 
next step, the sequence of the CK-18 gene was obtained as the target gene, and the sequence of the Glyceraldehyde 3-Phosphate Dehydrogenase (GAPDH) gene as the reference gene from the website (http://www.ncbi-nlm.nih.gov). Then direct and reverse nucleotide primers were designed by the OLIGO 7 software (Table 1), and the sequence of the primers was checked with the BLAST software. The primer sequence was checked in a human genome sequence in order to determine its presence, and the uniqueness of their attachment with the manufactured primers was verified by the pioneer gene transfer method. In order to perform Real-time PCR in this study, $2 \mu \mathrm{L}$ of RT- Reaction Solution (cDNA), $0.4 \mu \mathrm{L}$ of F and R primers, and $10 \mu \mathrm{l}$ of power SYBR GREEN PCR master mix were added to a micro-vial, the reaction volume attained was $20 \mu \mathrm{L}$ with Rnase-free water. The Real-time PCR reaction was performed on eightstripe streams, and was repeated at test three time. The temperature schedule for the examined genes was as follows: each complete amplification step was conducted by a separation step at $95{ }^{\circ} \mathrm{C}$ for $60{ }^{\circ} \mathrm{C}$ for 5 minutes, 45 cycles at $95{ }^{\circ} \mathrm{C}$ for 15 seconds, and $60{ }^{\circ} \mathrm{C}$ for 60 seconds, which was continued for the melting curve analysis. The SYBR green method was used for performing the melting curve analysis. The Real-time PCR reaction was performed for CK-18 gene as the target gene, and GAPDH as the reference gene for each patient and healthy sample. In this study, One-Step Real-Time PCR System of developed by the APPLIED BIOSYSTEM Company was used. The data was analyzed using the relative evaluation method. After calculating the amplification efficiency of the reaction primers, in order to use 2-ct $\Delta \Delta$ method. The Real-time PCR data analysis was performed based on the threshold cycle obtained for the target and reference genes in order to use the 2- $\Delta \Delta \mathrm{CT}$ method. The difference in between the mean CT of the reference gene from and the mean CT of the target gene was considered as the $\Delta \mathrm{CT}$ index, calculated for both the test and control groups. Also in addition, the difference between the CTs of the test and control groups was used to calculate the $\Delta \Delta \mathrm{CT}$ index, and then the expression ratio between test and control samples and then which changes the ratio of the expression changes between the two tests; and the ratio of the control samples was determined using the formula $<$ Ratio $=2-\Delta \Delta \mathrm{CT}>$.

Table 1. Primer sequence of CK-18 and GAPDH genes

\begin{tabular}{cc}
\hline \multicolumn{2}{c}{$\begin{array}{c}\text { Primer sequence used in Real-time PCR reaction } \\
\text { Primers } \\
\text { Sequence }\end{array}$} \\
\hline CK18-F & 5-GAGACGTACAGTCCAGTCCTTGG-3 \\
CK18-R & 5- CCACCTCCCTCAGGCTGTT -3 \\
GAPDH-F & 5- GAA GGT GAA GGT CGG AGT CA-3 \\
GAPDH-R & 5- TTG AGG TCA ATG AAG GGG TC-3 \\
\hline
\end{tabular}

\section{Results}

The melting curve analysis of the target and reference genes at the end of the RealTime PCR reaction determined that only one single product is reproduced. The results of the melting curve analysis of the CK-18 and GAPDH genes are shown in (Figure 1). The unique melting curve represents the absence of a non-specific product. The melting curves of the examined genes show only one curve with a specific peak, which reflects the specificity of the Real-time PCR product. In order to verify the quality of RNA, $1 \mu \mathrm{g}$ of the sample was examined by horizontal electrophoresis on $1 \%$ agarose gel 
(Figure 2). The observations showed that the 18s and 28s bands associated with RNA demonstrated the quality of the extracted RNA. In addition, the results of the quantitative evaluation of the mRNA extracted by the Nanodrop device showed that OD 260/280 nm of all extracted samples ranged between 1.87-1.94, thus indicating a high quality of extraction. In the analysis of the cDNA synthesis, the desired gene amplification reaction was performed in 35 cycles. After the completion of the reaction, $5 \mu \mathrm{L}$ of the sample was placed on $1 \%$ agarose to evaluate the quality of the gene segments after amplification. The expected band of the CK-18 and GAPDH genes are shown in (Figure 3). All the samples (patient and control) were examined quantitatively. Blood samples of 30 patients and 30 healthy individuals were used for the quantitative analysis after the extraction and synthesis of the cDNA. After the Realtime PCR was completed, the following curves were obtained, which showed the presence of an amplification curve in the samples of the patients, however there was none for the samples of the healthy subjects (Figure 4). Finally, the data was analyzed using the SPSS software and all the samples were tested for duplication. In order to examine whether there is a significant difference between the RQ and $\Delta \mathrm{CT}$, the independent t-test was performed. According to the result of this test, if the level of significance was less than 0.05 , it was concluded that there was a significant difference between the two variables (RQ and $\Delta \mathrm{CT}$ ); the result of this test is shown in (Table 2).

According to the aforementioned table, it is clear that the mean value of $\Delta \mathrm{CT}$ was 10.91 , with a standard deviation of 0.67 , and the mean of the RQ variable was 1.47 , with a standard deviation of 0.67 .

The calculated level of significance was 0.0000 , which is less than 0.005 . Therefore, it was concluded that there was a significant difference between the two variables RQ and $\Delta \mathrm{CT}$, and thus the hypothesis was confirmed. All of the samples expression level is shown in (Figure 5).
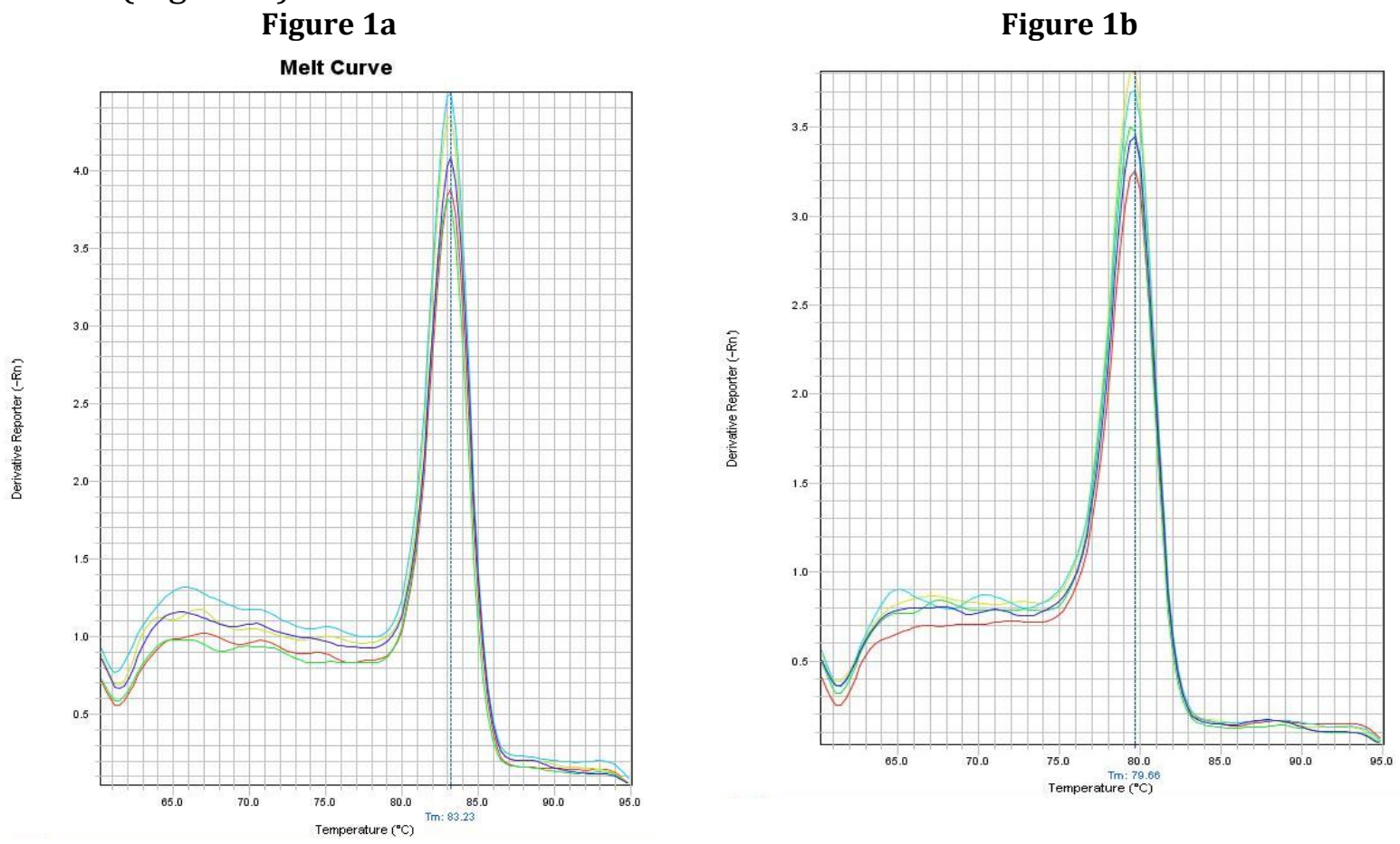

Figure 1. Graph of the melting curve of CK-18 (a). Graf of the melting curve of GAPDH (b) 


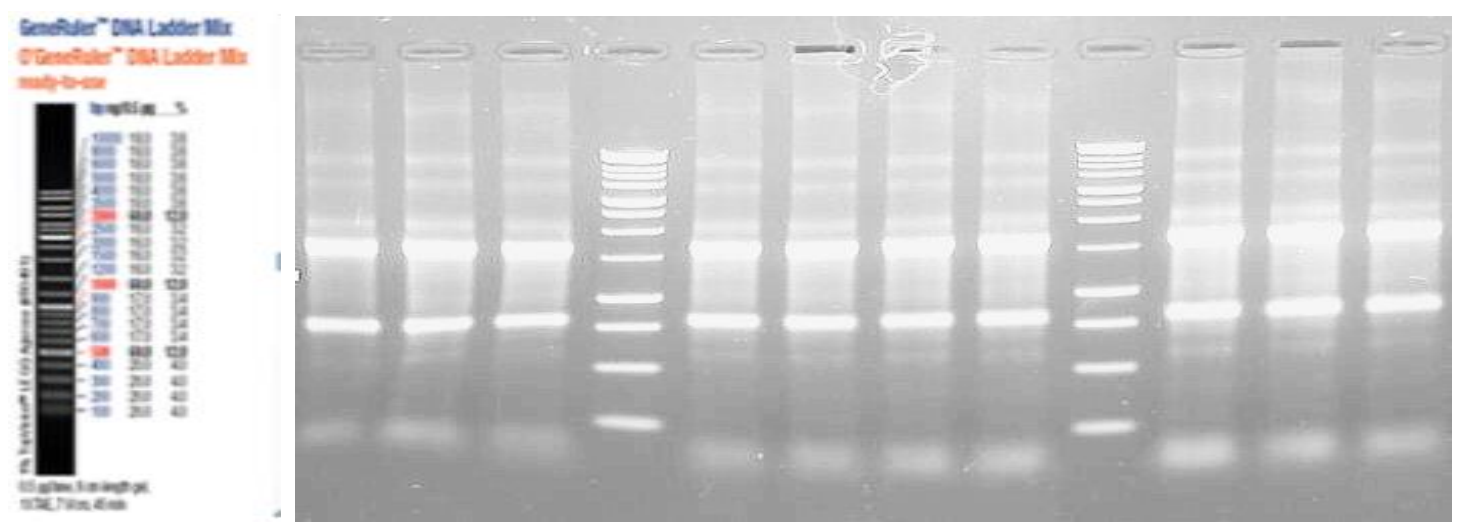

Figure 2. Extracted RNA samples on agarose gel. Observation of the $18 \mathrm{~s}$ and $28 \mathrm{~s}$ bands associated with Ribosomal RNA showed the quality of RNA extracted

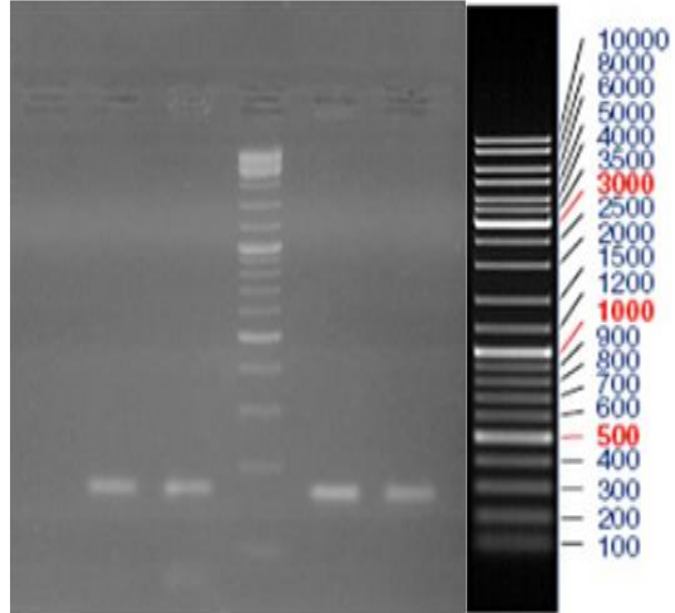

CK-18 Gene (a) View the presence of 280bp bond confirm the production.

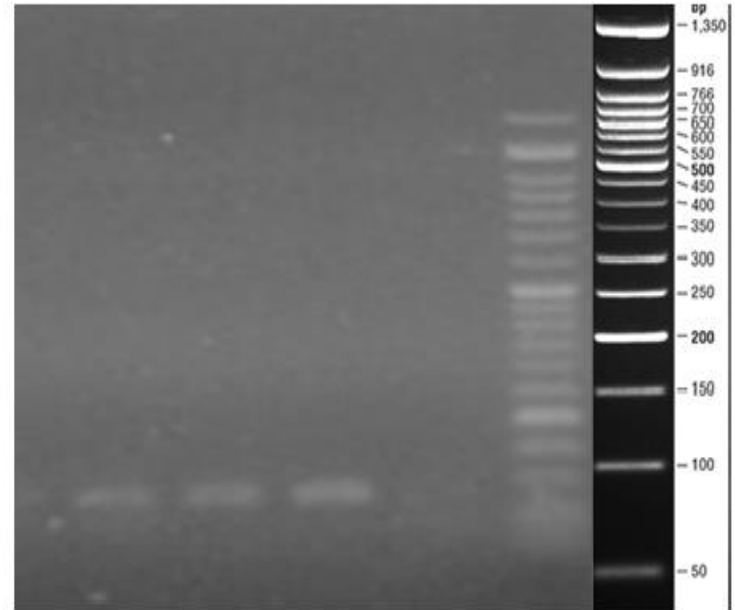

GAPDG gene (b) view the presence of 100bp bond confirm the production.

Figure 3. Analysis of the cDNA synthesis .after the completion of the reaction, $5 \mu$ of the sample was placed on 1\% Agarose to evaluate the quality of the gene segments after amplification. CK-18(a) and GAPDH (b)

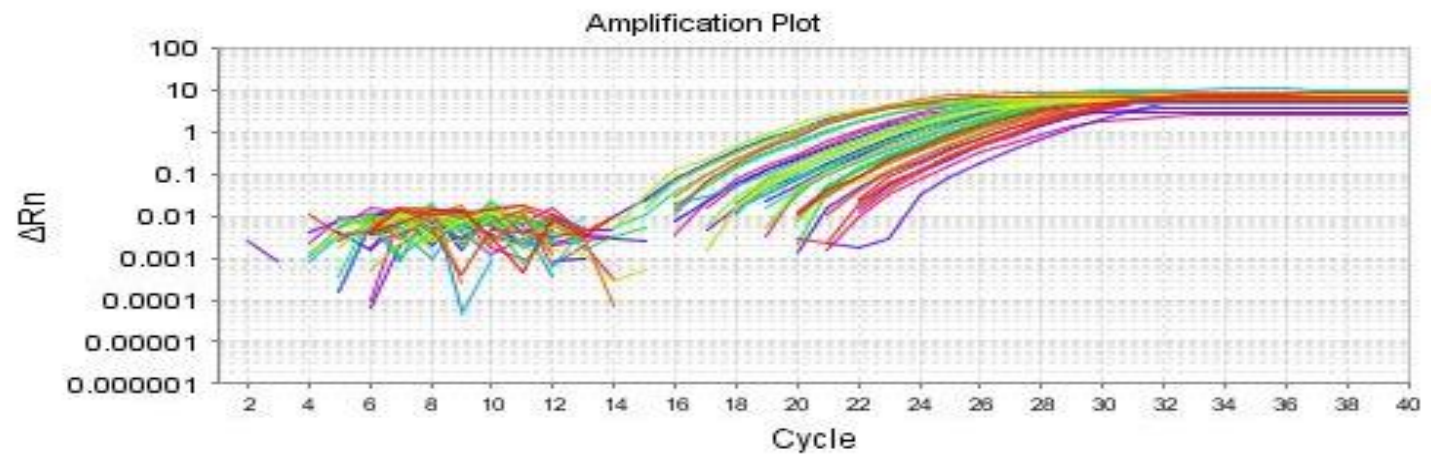

The GAPDH gene multiplication curve (a). Samples that have a higher titre start from the 14th cycle. In fact, this gene, as the house keeping gene, has growth charts in all healthy and diseased samples 


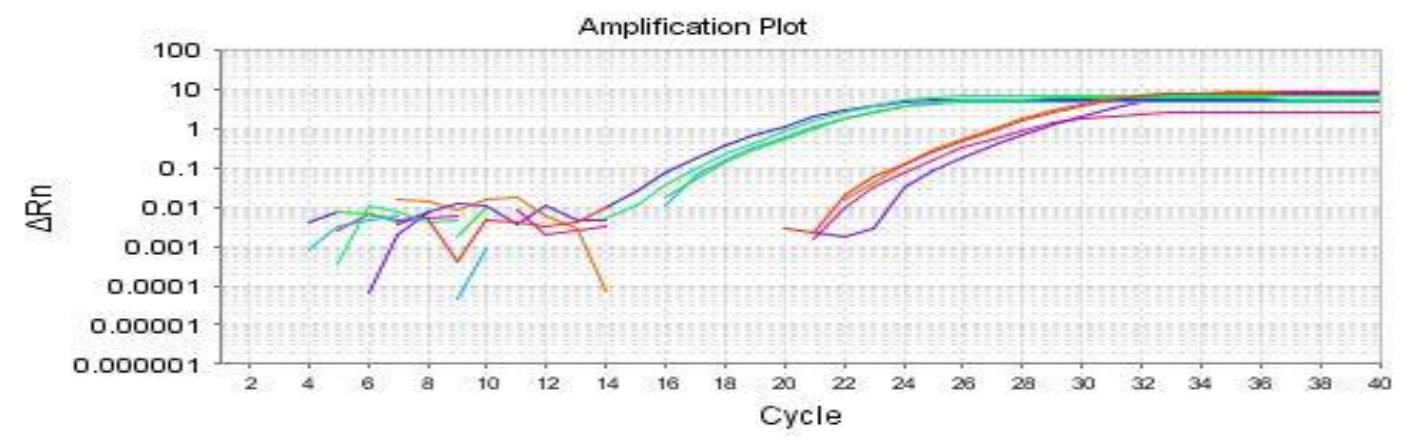

The CK-18 gene multiplication curve (b). Samples with higher titre started to rise from cycle 14, but the healthy group did not have a significant growth chart

Figure 4. Quantitative analysis of test and control samples using the real-time pcr technique GAPDH (a) and CK-18 (b)

Table 2. The independent t-test was used to examine the significant difference between the two variables $\mathrm{RQ}$ and $\Delta \mathrm{CT}$. According to the above table, it is clear that the mean of $\Delta \mathrm{CT}$ variables was 10.91 with a standard deviation of 0.67 and the mean of RQ was 1.47 with a standard deviation of 0.67

\section{Group Statistics}

\begin{tabular}{ccccc}
\hline & $\mathbf{N}$ & Mean & Std. Deviation & Std. Error Mean \\
\hline$\Delta \mathrm{CT}$ & 30 & 10.9107 & .67180 & .12265 \\
$\mathrm{RQ}$ & 30 & 1.4739 & .67155 & .12261 \\
\hline
\end{tabular}

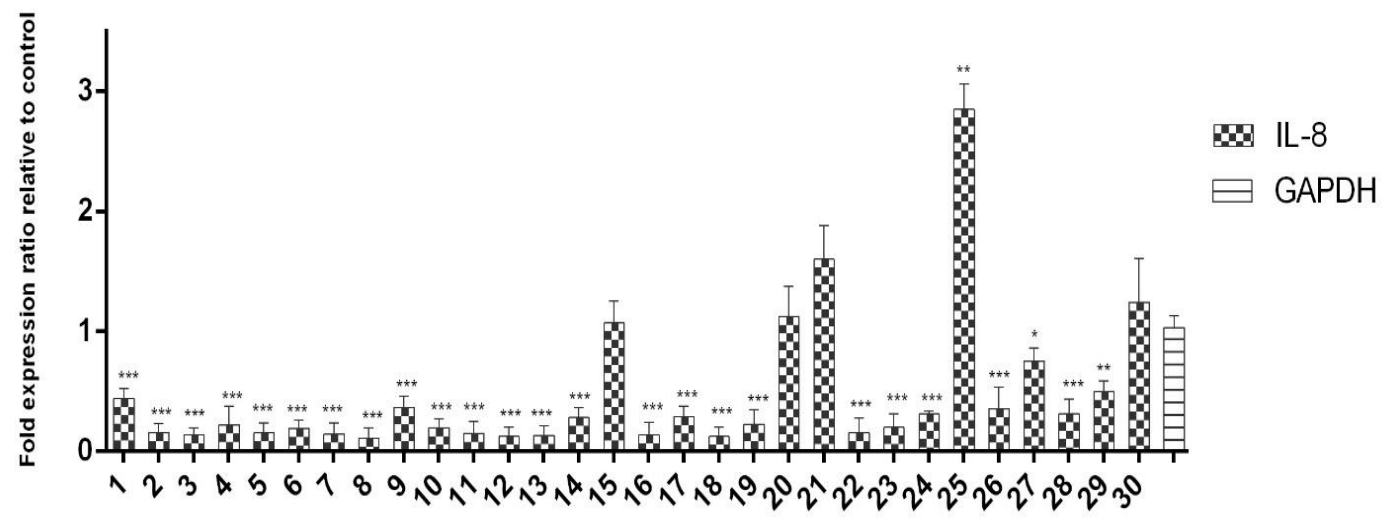

Figure 5. Expression of the ck-18 tumor marker in the breast cancer patients

\section{Discussion}

Prompt prevention and diagnosis of cancer are associated with easier and less costly treatments. Late diagnosis, besides psychological and financial issues, can often lead to the death of patient. Hence, a non-invasive method with a high diagnostic sensitivity and specificity is always required. The aim of this study was to find a specific marker that is technically applicable to most medical diagnostic laboratories. 
Moll R et al., in article published in the CELL Journal in 1982, Varadhachary GR and this colleagues, in their work in the CANCER journal in 2004, Gasterson BA, in their work in the Breast Cancer Journal in 2005, PRK YJ, in this work in 2007, and Toyoshima T, in this work in 2008, examined the different types of CKs in various kinds of cancers, and found the relationship between the cancers and dependent cytokeratins. In 2012, Shao MM, in China, investigated the CK expression in breast cancer by the IHC method, and observed the expression of CK7-8, 18 and 19 in $90 \%$ of the breast cancer specimens. In 2012, B. Rattan and colleagues also conducted a study on the CK-18 expression in breast cancer using the immunohistochemistry technique, in which they showed that the expression of both tumor markers were simultaneously positive in patients with metastasis. In 2016, Ignacio Cruz studied the effect of several parameters by flow cytometry for the diagnosis of breast cancer, in which he confirmed the presence of CK-18 in serum. Finally, in the present study, serum samples from 30 patients who had not yet started chemotherapy and radiotherapy had been collected, isolated, and their total RNA, were extracted. After designing the primers for CK-18 and GAPDH, the RNA was converted to cDNA and the qualitative analysis using PCR showed the presence of positive CK-18 expression in patients, which was negative in the healthy group. Furthermore, we investigated the quantitative method by Real-Time PCR, which demonstrated a positive CK-18 expression in the patients, serum. In addition, according to the disease grade, the CK-18 expression was different in the patients serum. The benefits of this examination was the minimal invasiveness of the procedure. The Real-Time PCR method is cheaper and easier compared to the IHC method, and it yields more accurate results in a shorter period of time.

\section{References}

Alix-Panabieres, C, Vendrell, JP, Slijper, M, Pellé 0, Barbotte E, Mercier G, Jacot W, Fabbro M, Pantel K. (2009). Full- length cytokeratin-19 is released by human tumor cells: a potential role in metastatic progression of breast cancer. Breast cancer Res, 11(3):R39.

Allard, WJ, Matera, J, Miller, MC, Repollet, M, Connelly, MC, Rao, C, Tibbe, AG, Uhr, JW, Terstappen, LW. (2004). Tumor cells circulate in the peripheral blood of all major carcinomas but not in healthy subjects or patients with nonmalignant diseases. Clin Cancer Res, 10(20):6897-6904.

American cancer society. Prevention and early detection, Tumor Markers. American cancer society $2015 ; 29$.

Baccelli, I, Schneeweiss, A, Reithdorf, S, Stenzinger, A, Schillert, A, Vogel, V, Klein, C, Saini, M, Bauerle, T, Wallwiener, M, Holland-Letz T, Höfner T, Sprick M, Scharpff M, Marmé F, Sinn HP, Pantel K, Weichert W, Trumpp A. (2013). Identification of a population of blood circulating tumor cells from breast cancer patients that initiates metastasis in a xenograft assay. Nat Biotechnol, 31(6):539-544.

Bernard, PS, Wittwer, CT. (2002). Real-Time PCR technology for cancer diagnostics. Clin Chem, 48(8):1178-1185.

Chu, PG, Weiss, LM. (2002). Keratin expression in human tissues and neoplasms. Histopathology, 40(5):403-439. [PubMed] 
Choy, A, McCulloch, PG. (1993). Detection and enumeration of circulating tumor cells in colorectal cancer. Br J Surg, 80:1490.

Cristofanilli, M, Budd, GT, Ellis, MJ, Stopeck, A, Matera, J, Miller, MC, Reuben JM, Doyle, GV, Allard, WJ, Terstappen, LW, Hayes DF. (2004). Circulating tumor cells, disease progression, and survival in metastatic breast cancer. $N$ Engl J Med, 351:781-791.

DeSantis, CE, Fedewa, SA, Goding Sauer, A, Goding Sauer A, Kramer JL, Smith RA. (2016), Breast cancer statistics, 2015: convergence of incidence rates between black and white women. Ca cancer J Clin, 66(1):31-42.

Dive, C., Smith RA, Garner E, Ward T, George-Smith SS, Campbell F, Greenhalf W, Ghaneh P, Neoptolemos JP. (2010). Considerations for the use of plasma cytokeratin 18 as a biomarker in pancreatic cancer. BrJ Cancer, 102(3):577-582.

[Internet] WHO: Geneva, Switzerland. Breast cancer .http://www.who.int/cancer/prevention/diagnosis-screening/breast-cancer/en/

Katapodi, MC, Dodd, MJ, Lee, KA, Facione, NC. (2009). Underestimation of Breast Cancer Risk: Influence on Screening Behavior. Oncol Nurs Forum, 36(3):306-314.

Makarovskiy, AN, Ackerley, W, Wojcik, L, Halpert, GK, Stein, BS, Carreiro, MP, Hixson, DC. (1997). Application of immunomagnetic beads in combination with RT-PCR for the detection of circulating prostate cancer cells. J Clin Lab Anal, 11(6):346-350.

Naoe, M, Ogawa, Y, Morita, J, Omori, K, Takeshita, K, Shichijyo, T, Okumura, T, Igarashi, A, Yanaihara, A, Iwamoto, S, Fukagai T, Miyazaki A, Yoshida H. (2007). Detection of circulating urothelial cancer cells in the blood using the CellSearch System. Cancer, 109:1439-1445.

Salehi Nodeh, A, Ghafouri, S, Razavi, S, Mirshafie, SA. (2008). Assessment of TPS tumor marker with ELISA for early detection and monitoring of Breast cancer. Payavard Salamat, 2:84-88.

Schrohl AS, Holten-Andersen M, Sweep F, Schmitt M, Harbeck N, Foekens J, Brünner N. (2003). Tumor markers from laboratory to clinical utility. Mol Cell Proteomics, 2(6):378387.

Shao, MM, Chan, SK, Yu, AM, Lam, CC, Tsang JY, Lui PC, Law BK, Tan PH, Tse GM. (2012). Keratin expression in breast cancers. Virchows Arch, 461(3):313-322.

Siegel, R., Ma, J, Zou, Z, Jemal, A. (2014). Cancer statistics, 2014. Ca Cancer J Clin, 64(1):9-29. [PubMed]

Siegel, RL, Miller, KD, Jemal, A. (2017). Cancer statistics, 2017, Ca cancer J Clin, 67(1):7-30.

Stevart, BW, Wild, CP. (2014). World Cancer Report, Geneva, Switzerland: WHO press.

Wolfrum, F, Vogel, I, Fandrich, F, Kalthoff, H. (2005). Detection and clinical implications of minimal residual disease in gastro-intestinal cancer. Langenbecks Arch Surg, 390:430-441. 
Zhang, L, Ridgway, LD, Wetzel, MD, Ngo, J, Yin, W, Kumar, D, Goodman, JC, Groves, MD, Marchetti, D. (2013). The identification and characterization of breast cancer CTCs competent for brain metastasis. Sci. Transl. Med, 5(180):180ra48.

How to cite this article: Armin Gharibi, Roudabeh Behzadi Andouhjerdi, Evaluation of the Expression of the CK-18 Tumor Marker in Blood Samples of Breast Cancer Patients using Real-Time PCR. International Journal of Advanced Biological and Biomedical Research, 2019, 7(2), 142-150. Link: http://www.ijabbr.com/article 34413.html 